\title{
Paramagnetic Iron-Doped Hydroxyapatite Nanoparticles with Improved Metal Sorption Properties. A Bioorganic Substrates- Mediated Synthesis
}

\author{
D. Fabio Mercado, ${ }^{\dagger}$ Giuliana Magnacca, ${ }^{\ddagger}$ Mery Malandrino, ${ }^{\ddagger}$ Aldo Rubert, ${ }^{\dagger}$ Enzo Montoneri, ${ }^{\ddagger}, \#$ \\ Luisella Celi, ${ }^{\S}$ Alessandra Bianco Prevot, ${ }^{\dagger}$ and Mónica C. Gonzalez*,† \\ ${ }^{\dagger}$ Instituto de Investigaciones Fisicoquímicas Teóricas y Aplicadas (INIFTA), CCT-La Plata-CONICET, Universidad Nacional de La \\ Plata, La Plata, Buenos Aires 1900, Argentina \\ ${ }^{\ddagger}$ Dipartimento di Chimica, Università di Torino, Via Giuria 7, Torino, Torino 10125, Italy \\ ${ }^{\S}$ Dipartimento di Scienze Agrarie, Forestali e Alimentari, Università di Torino, Via Leonardo Da Vinci, 44 - Grugliasco, Torino, \\ Torino 10095, Italy
}

\section{Supporting Information}

ABSTRACT: This paper describes the synthesis of paramegnetic iron-containing hydroxyapatite nanoparticles and their increased $\mathrm{Cu}^{2+}$ sorbent capacity when using $\mathrm{Ca}^{2+}$ complexes of soluble bioorganic substrates from urban wastes as synthesis precursors. A thorough characterization of the particles by TEM, XRD, FTIR spectroscopy, specific surface area, TGA, XPS, and DLS indicates that loss of crystallinity, a higher specific area, an increased surface oxygen content, and formation of surface iron phases strongly enhance $\mathrm{Cu}^{2+}$ adsorption capacity of hydroxyapatite-based materials. How-

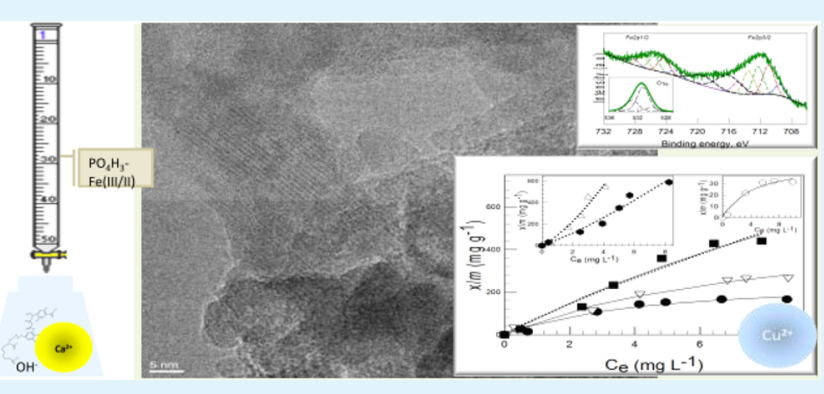
ever, the major effect of the surface and morphologycal modifications is the size diminution of the aggregates formed in aqueous solutions leading to an increased effective surface available for $\mathrm{Cu}^{2+}$ adsorption. Maximum sorption values of $550-850 \mathrm{mg} \mathrm{Cu}{ }^{2+}$ per gram of particles suspended in an aqueous solution at $\mathrm{pH} 7$ were determined, almost 10 times the maximum values observed for hydroxyapatite nanoparticles suspensions under the same conditions.

KEYWORDS: magnetic nanomaterials, $\mathrm{Cu}^{2+}$ sorption, effective surface, bioorganic substrates, surface chemistry

\section{INTRODUCTION}

Hydroxyapatite $(\mathrm{Ap}), \mathrm{Ca}_{10}\left(\mathrm{PO}_{4}\right)_{6}(\mathrm{OH})_{2}$, the main component of the bone tissue of vertebrates, is one of the most promising sorbent materials for removing actinides and heavy metals from wastewaters and soils. Apatites of the most different origins, such as cow bone charcoal, ${ }^{1}$ nano-Ap (nAp), ${ }^{2}$ waste oyster shells, ${ }^{3}$ and bacteria, ${ }^{4}$ were used for the removal of heavy metals. Ap is an ideal material for long-term sequestration in aqueous reservoirs because of its chemical stability across a wide range of geological conditions, ${ }^{5}$ high biocompatibility, strong ability to fix actinides and heavy metals, ${ }^{6}$ and maximum metal ion sorption capacity at $\mathrm{pH} 6-7 .^{2}$

Humates are also widely applied to clean up toxic waste sites. Formation of humates is based on the ability of carboxyl and hydroxyl groups of humic and/or fulvic acids to bind metal cations. In particular, $\mathrm{Ca}^{2+}$ are effective precipitators of humates and provide a route for the transfer of trace metals from the solution to the solid phase. ${ }^{7}$ Moreover, formation of stable, water-soluble phosphate- $\mathrm{Ca}^{2+}$-humic complexes ${ }^{8}$ were reported. Urban biowastes (UBW) have been reported to contain soluble humic-like substances known as bioorganic substances (SBO) which show promise as chemical auxiliaries for a number of technological applications in the chemical industry and in environmental remediation. ${ }^{9}$ UBW-SBO are mixtures of substances with molecular weights in the range $(1-3) \times 10^{5}$ $\mathrm{Da}$, formed by long aliphatic $\mathrm{C}$ chains substituted by aromatic rings and $\mathrm{COOH}, \mathrm{NCO}, \mathrm{C}=\mathrm{O}, \mathrm{PhOH}, \mathrm{O}$-alkyl, O-aryl, OCO, $\mathrm{OMe}$, and alkyl amines functional groups. Therefore, the use of UBW-SBO as templates in the synthesis of Ap materials may be expected to affect Ap morphology and surface chemistry, as observed for organic matrix-mediated fabrication of nanostructured hydroxyapatite biocomposites. ${ }^{10}$

Nanomaterials showing high specific surface area and tunable surface chemistry were suggested to offer significant improvement as metal adsorbents. ${ }^{11}$ In particular, magnetite-incorporated hydroxyapatite composites attract much attention as a magnetic functional material for developing adsorbents and catalysts since they could be easily removed by application of a

Received: November 19, 2013

Accepted: February 21, 2014

Published: February 21, 2014 
magnetic field. ${ }^{12}$ However, to date, the metal adsorption capacity of these materials was not assessed.

In this context, in the present comunication we describe the synthesis of Ap-based magnetic nanoparticles and their increased metal sorption capacity when synthetized using $\mathrm{Ca}^{2+}$ complexes of UBW-SBO as synthesis precursors.

\section{EXPERIMENTAL SECTION}

Reactants. Calcium hydroxide 95 wt \%, phosphoric acid $85 \%$, $\mathrm{FeCl}_{2} \cdot 4 \mathrm{H}_{2} \mathrm{O}>99$ wt \%, $\mathrm{FeCl}_{3} \cdot 6 \mathrm{H}_{2} \mathrm{O} 97$ wt \%, were supplied by Sigma Aldrich and used without further purification. Deionized water was Milli- $Q$ purified (18.2 $\mathrm{M} \Omega \mathrm{cm}$ and $6 \mathrm{ppb}$ TOC). When required, $\mathrm{pH}$ was stabilized to 7.0 with 4-(2-hydroxyethyl)piperazine-1-ethanesulfonic acid, sodium salt (HEPES-Na), and nitric acid.

The bioorganic substances herein used were available from a pilot plant from Studio Chiono \& Associati in Rivarolo Canavese, Italy. The fraction of soluble biorganic substances used, namely CVT230, was extracted from home gardening and park trimming residues aerated for 230 days for aerobic microbiological treatment; the resulting biomass was digested with an alkali solution at $65^{\circ} \mathrm{C}$ for several hours, and the remaining supernatant was filtered by an UF membrane operating with tangential flow to yield a retentate with $5-10 \%$ dry matter content. The concentrated retentate (CVT230) was finally dried at $60{ }^{\circ} \mathrm{C}$. CVT230 was $72.1 \%$ solid residue and composed of $38.25 \pm 0.09 \% \mathrm{w} /$ w C and $4.01 \pm 0.03 \% \mathrm{w} / \mathrm{w} \mathrm{N}$. Among the important mineral residues are the following: $256 \mathrm{ppm} \mathrm{Zn,} 202 \mathrm{ppm} \mathrm{Cu}, 92 \mathrm{ppm} \mathrm{Ni}, 85 \mathrm{ppm} \mathrm{Pb}$, $19 \mathrm{ppm} \mathrm{Cr}$, and minor amounts of $\mathrm{Si}, \mathrm{Fe}$, and $\mathrm{Ca}$. CVT230 carbon fractions are as follows: $37 \%$ alifatic, $20 \%$ aromatic, $14 \%$ alkoxy, $12 \%$ carboxylic, and $7 \%$ are in an $\alpha$ position to amines. ${ }^{13} \mathrm{SBO}$ were reported to be nontoxic to Vibrio fischeri, activated sludge bacteria, Daphnia magna, and Pseudokirchneriella subcapitata. Their reported biological to chemical oxygen demand ratio, BOD:COD $<0.1$, indicates an extremely low biodegradability.

Addition of excess $\mathrm{Ca}^{2+}$ to $\mathrm{SBO}$ aqueous solutions of $\mathrm{pH} 11$ leads to the formation of insoluble $\mathrm{SBO}-\mathrm{Ca}^{2+}$ products which became solubilized on decreasing the $\mathrm{pH}$ to 5 . The observed behavior resembles that of humic and fulvic acids complexation with $\mathrm{Ca}^{2+}$ ions. $^{14}$

Synthesis of Hydroxyapatite Magnetic Nanoparticles. A modification of literature methods was used for the synthesis of hydroxyapatite nanoparticles, nAp. ${ }^{15}$ Briefly, a suspension of $\mathrm{Ca}(\mathrm{OH})_{2}$ ( $5 \mathrm{~g}$ in $40 \mathrm{~mL}$ of $\mathrm{H}_{2} \mathrm{O}$ ) was stirred and heated to $80^{\circ} \mathrm{C}$. A phosphoric acid solution $\left(4.44 \mathrm{~g}\right.$ in $60 \mathrm{ml}$ of $\mathrm{H}_{2} \mathrm{O}$ ) was added dropwise into the calcium hydroxide suspension over a period of $2 \mathrm{~h}$ under constant heating and stirring, to obtain a suspension of $\mathrm{nAp}$. The precipitate was separated from the mother liquor by centrifugation, washed several times with deionized water, and dried at $80^{\circ} \mathrm{C}$.

The previous process was adapted for the synthesis of $\mathrm{Fe}$-containing hydroxyapatite nanoparticles, denoted as $\mathrm{Fe}-\mathrm{nAp}$. A FeCl $\mathrm{Fe}_{2} \cdot 4 \mathrm{H}_{2} \mathrm{O}(1.27$ g), $\mathrm{FeCl}_{3} \cdot 6 \mathrm{H}_{2} \mathrm{O}(1.79 \mathrm{~g})$ phosphoric acid $\left(4.44 \mathrm{~g}\right.$ in $60 \mathrm{~mL}$ of $\left.\mathrm{H}_{2} \mathrm{O}\right)$ solution was added dropwise into a $\mathrm{Ca}(\mathrm{OH})_{2}$ suspension $(5 \mathrm{~g}$ in 40 $\mathrm{mL}$ of $\mathrm{H}_{2} \mathrm{O}$ ) over a period of $2 \mathrm{~h}$ under constant stirring and heating at $80{ }^{\circ} \mathrm{C}$. The total amounts of iron to calcium ions were adjusted to obtain an analytical molar ratio of $\mathrm{Fe} / \mathrm{Ca}=0.2$. The reaction products were kept in suspension with constant stirring for $24 \mathrm{~h}$ at room temperature. The precipitate was separated from the mother liquor either by centrifugation or by means of a laboratory magnet bar of ca. $2000 \mathrm{G}$, then washed several times with deionized water, and dried at $80{ }^{\circ} \mathrm{C}$.

For the synthesis of SBO-templated iron-containing hydroxyapatite nanoparticles, either 20,200 , or $1000 \mathrm{mg}$ of SBO were dissolved in a $\mathrm{Ca}(\mathrm{OH})_{2}$ suspension $\left(5 \mathrm{~g}\right.$ in $40 \mathrm{ml}$ of $\mathrm{H}_{2} \mathrm{O}$ ), and the resulting suspension was stirred for $2 \mathrm{~h}$ at $80^{\circ} \mathrm{C}$. A FeCl $2 \cdot 4 \mathrm{H}_{2} \mathrm{O}(1.27 \mathrm{~g}), \mathrm{FeCl}_{3}$. $6 \mathrm{H}_{2} \mathrm{O}(1.79 \mathrm{~g})$ phosphoric acid $\left(4.44 \mathrm{~g}\right.$ in $60 \mathrm{~mL}$ of $\left.\mathrm{H}_{2} \mathrm{O}\right)$ solution was then added dropwise into the $\mathrm{Ca}(\mathrm{OH})_{2}-\mathrm{SBO}$ suspension over a period of $2 \mathrm{~h}$ under constant stirring and heating at $80{ }^{\circ} \mathrm{C}$. The reaction mixture was kept in suspension with constant stirring for $24 \mathrm{~h}$ at room temperature. The precipitate was separated from the mother liquor by centrifugation and by means of a laboratory magnet bar and then washed several times with deionized water until no SBO was observed in the washing liquors by, both, UV-vis spectroscopy and total organic carbon assays. All the particles were dried at $80^{\circ} \mathrm{C}$. The particles were named 0.05SBO-Fe-nAp, 0.5SBO-Fe-nAp, and 2.5SBOFe-nAp, according to the $\mathrm{SBO} / \mathrm{Ca} \mathrm{w} / \mathrm{w}$ ratio used in the synthesis. When required, 2.5SBO-Fe-nAp powders were further calcined at 600 ${ }^{\circ} \mathrm{C}$ for $3 \mathrm{~h}$. Calcined particles are therefore named 2.5SBO-Fe-nAp-cal.

Particle Characterization. The crystalline phase content of samples was assessed by X-ray Diffraction (XRD) by using a PW3040/60 X'Pert PRO MPD X-ray diffractometer from PANalytical, in Bragg-Brentano geometry, equipped with the high power ceramic tube PW3373/10 LFF source with $\mathrm{Cu}$ anode. The qualitative phase analysis was performed with the EVA software package and compared to the ICDD-PDF-2- database. The effect of Fe and SBO treatment on nAp crystallites domain size, $D_{v}$, were evaluated. A lower limit value of $D_{\mathrm{v}}$ was calculated employing the Scherrer equation relating the size of submicrometre particles in a solid to the broadening of diffraction pattern main peaks ${ }^{17}$ and considering $k=0.9$ as the shape factor and $\lambda$ $=0.154056 \mathrm{~nm}$ as the wave length of the $\mathrm{X}$-rays for $\mathrm{Cu} \mathrm{K} \alpha 1$ radiation.

High resolution transmission electron microscopy (HRTEM) studies were carried out on a JEOL JEM 3010UHR (300 kV) TEM fitted with a single crystal $\mathrm{LaB}_{6}$ filament. Samples were dry deposited on $\mathrm{Cu}$ "holey" carbon grids (200 mesh).

The thermal behavior of the powders was studied by thermal gravimetric analysis (TGA) using a Q600 TA Instruments. The program used a nitrogen environment and involved a one minute initial temperature of $50{ }^{\circ} \mathrm{C}$, followed by a $20^{\circ} \mathrm{C} / \mathrm{min}$ ramp up to 800 ${ }^{\circ} \mathrm{C}$, and maintained at this temperature for 10 minutes. For some samples, an oxygen environment was also used.

The functional groups present in the prepared nanoparticles were identified by their IR spectrum obtained with a Bruker IFS28 spectrophotometer equipped with a Globar source and a DTGS detector working at 128 scans with $4 \mathrm{~cm}^{-1}$ resolution in the overall range $4000-400 \mathrm{~cm}^{-1}$. Samples were prepared by pressing a grounded mixture of $1 \%$ of the particles powder with $99 \%$ dry $\mathrm{KBr}$ at a load of 5 tons.

Nitrogen gas-volumetric adsorption experiments for specific surface area determinations (BET model) were performed at $77 \mathrm{~K}$ by means of a ASAP2020 by Micromeritics model. Before each measurement, samples were outgassed overnight at $80{ }^{\circ} \mathrm{C}$ at a residual pressure of about $10^{-2}$ mbar to guarantee a good cleaning of the sample surface.

The X-ray photoelectron spectroscopy (XPS) spectra were obtained under UHV with a XR50 Specs $\mathrm{GmbH}$ spectrometer using $\mathrm{Mg} \mathrm{K}(\alpha)$ as the excitation source and a PHOIBOS 100 half sphere electron energy analyzer. A two-point calibration of the energy scale was performed using sputtered cleaned gold $(\mathrm{Au} 4 \mathrm{f} 7 / 2$, binding energy (BE) $84.00 \mathrm{eV}$ ) and copper (Cu 2p3/2, BE: $932.67 \mathrm{eV}$ ) samples. Internal calibration to correct for surface charging was performed with the $\mathrm{C} 1 \mathrm{~s}$ peak at $\mathrm{BE}=284.6 \mathrm{eV}$ due to adventitious carbon. High resolution XPS spectra were taken to get a better insight into the chemical environment of the different atoms. A Shirley-type background from each spectrum was used to remove the effect of the extrinsic structure loss and the espectrum resolved by GaussianLorentzian fitting, keeping $\chi 2$ values to their minimum values.

The electrophoretic mobility was measured by Laser Doppler Velocimetry-Photon Correlation Spectroscopy using a DELSA 440 spectrometer (Beckman Coulter Electronics, Hialeah, FL) equipped with a $5 \mathrm{~mW}$ HeNe laser $(632.8 \mathrm{~nm})$.

The magnetic characteristics of the particles were assessed using a Lakeshore 7403 vibrating sample magnetometer. Magnetization of dried samples was performed at room temperature up to a maximum field of 1.9T.

Metal determinations were performed with a Perkin Elmer Optima 7000 DV Model inductively coupled plasma atomic emission spectrometer (ICP-AES). The instrument is equipped with a Echelle monochromator, a cyclonic spray chamber, and a PTFE Mira Mist nebulizer. The instrumental conditions were as follows: plasma power $1.3 \mathrm{~kW}$; sample aspiration rate $1.2 \mathrm{~mL} / \mathrm{min}$; argon cooling flow $1.5 \mathrm{~L} /$ min; argon sampling flow $0.6 \mathrm{~L} / \mathrm{min}$. The overall $\mathrm{P}: \mathrm{Ca}$ :Fe ratio of the 
Scheme 1. Flow Chart of the Synthesis Pathways Used for Obtaining the Different Particles ${ }^{a}$

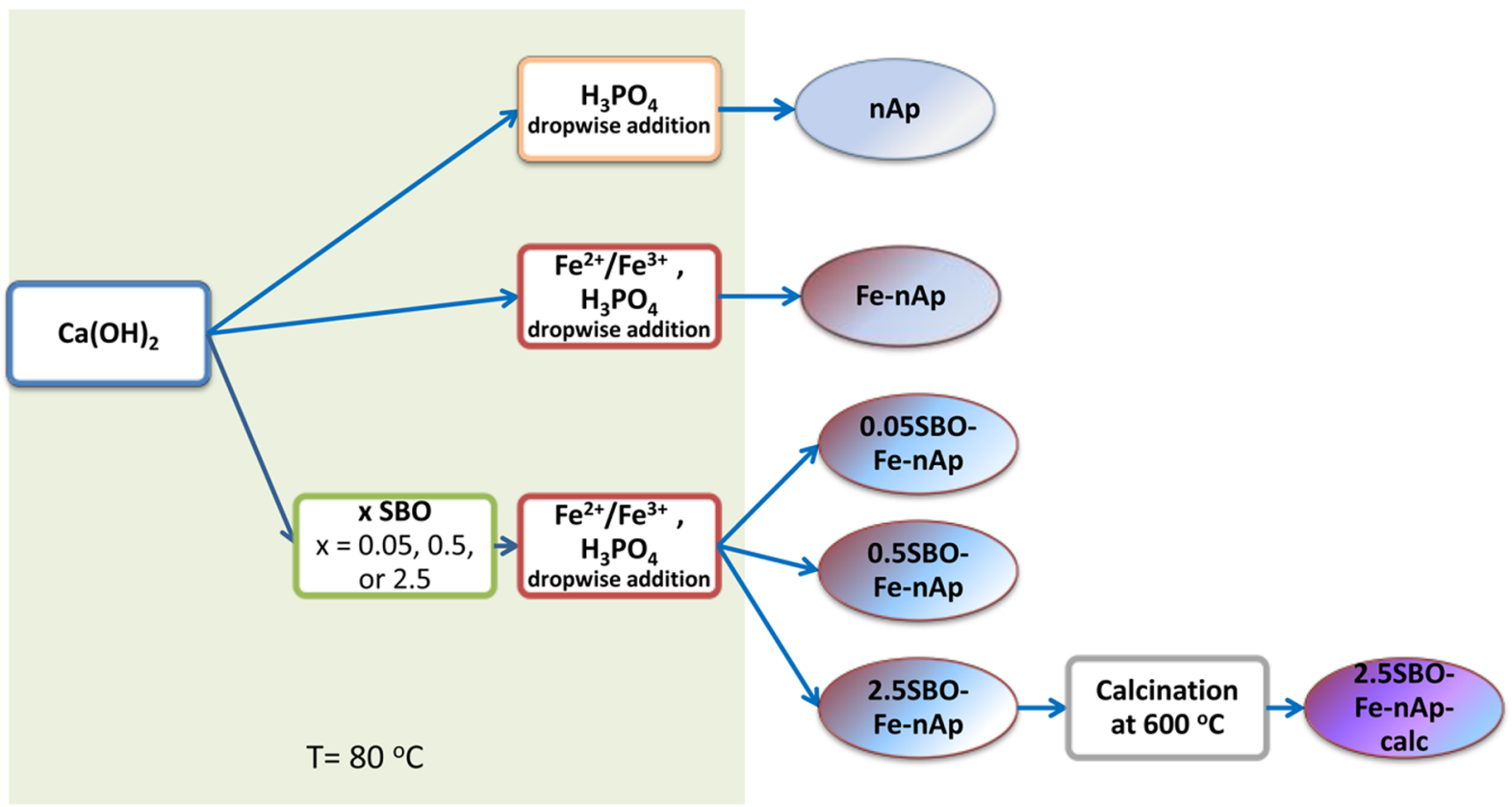

a " $\mathrm{x}$ " denotes the $\mathrm{SBO} / \mathrm{Ca} \mathrm{w} / \mathrm{w}$ analytical ratio after mixing.

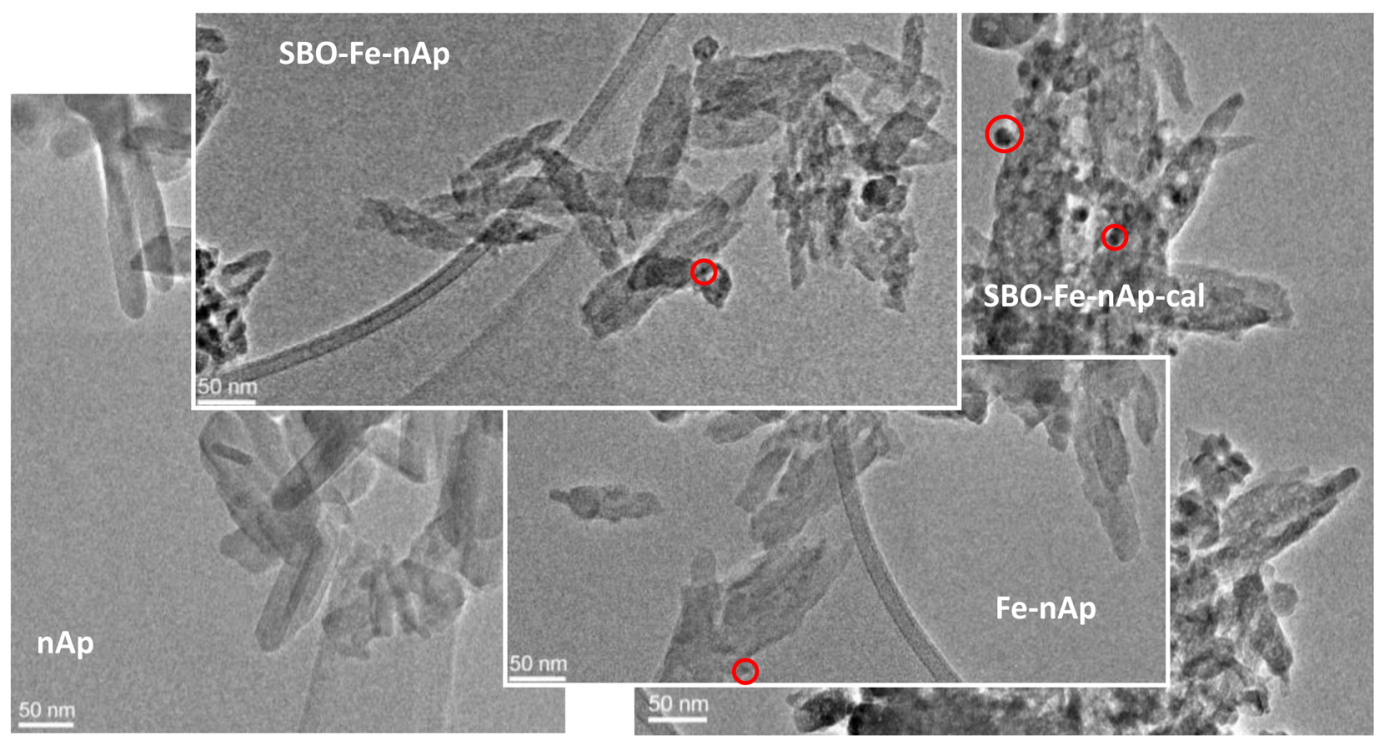

Figure 1. HRTEM micrographs. Circles show iron-containing domains.

synthetized particles was also measured by ICP after acid digestion of the particles.

Metal Adsorption Experiments. Adsorption studies were conducted in batch experiments. Variable mL-aliquots of a $\mathrm{Cu}\left(\mathrm{NO}_{3}\right)_{2}$ stock solution of $1000.0 \mathrm{mg} \mathrm{L}^{-1}$ were mixed with $5 \mathrm{~mL}$ of a $100 \mathrm{ppm}$ solution of either nAp, Fe-nAp, 0.05SBO-Fe-nAp, 0.5SBO-Fe-nAp, 2.5SBO-Fe-nAp, or 2.5SBO-Fe-nAp-cal and further diluted to a final volume of $25 \mathrm{~mL}$ with a solution of 4-(2-hydroxyethyl)piperazine-1ethanesulfonic acid sodium salt (HEPES-Na) of $\mathrm{pH} 7$ and $0.01 \mathrm{M}$ ionic strength. The highest $\left[\mathrm{Cu}^{2+}\right]$ used was limited by $\mathrm{Cu}^{2+}$ solubility. ${ }^{18}$

The suspensions were shaken at room temperature $\left(25 \pm 2^{\circ} \mathrm{C}\right)$ for several hours until equilibration was observed. Preliminary experiments showed that equilibration takes place already after one hour. The supernatant and solid residues were separated by centrifugation at 4,000 rpm for $10 \mathrm{~min}$. The $\mathrm{Cu}$ concentration in the supernatant solutions was determined by ICP-AES. The amount of adsorbed $\mathrm{Cu}$ was calculated according to $x / m=v \times\left(C_{\mathrm{o}}-\mathrm{C}_{\mathrm{e}}\right) / m$, where $x / m(\mathrm{mg}$ $\left.\mathrm{g}^{-1}\right)$ is the weight in $\mathrm{mg}$ of $\mathrm{Cu}^{2+}$ ions adsorbed per $\mathrm{g}$ of particles, $C_{\mathrm{o}}$ and $C_{\mathrm{e}}\left(\mathrm{mg} \cdot \mathrm{L}^{-1}\right)$ stand for the initial and equilibrium $\mathrm{Cu}^{2+}$ concentrations in solution, respectively, $v(\mathrm{~L})$ is the solution volume used in the experiment, and $m(\mathrm{~g})$ is the mass of particles used. Data were expressed as the mean of three replicates.

\section{RESULTS AND DISCUSSION}

A flow chart of the pathways followed for the synthesis of the different particles is described in Scheme 1.

Particle Characterization. The effect of SBO and Fe on the physical and chemical properties of nAp was studied and compared with untreated nAp. Figure 1 shows comparative HRTEM micrographs of the prepared powders. Due to substantial agglomeration it is not possible to obtain a statistic analysis of the particles size. However, the micrographs show 
cylindrical, 100-150 nm length, crystalline nAp particles, as indicated by the presence of interference fringe patterns observable at high resolution. Fe-nAp particles show somewhat shorter $(50-100 \mathrm{~nm})$ acicular shapes of irregular contour. The latter observation is in line with the reported effect on the morphology of rodlike nanometer size crystalline nAp which became elongated and the crystallinity slightly lowered upon addition of $\mathrm{Fe}$ (III) ions, ${ }^{19}$ vide infra. Inhibition of hydroxyapatite $c$-axis and promotion of the $a$-axis by added $\mathrm{Fe}(\mathrm{II})$ during a coprecipitation synthesis was also reported. ${ }^{20}$

The use of $2.5 \mathrm{w}(\mathrm{SBO}) / \mathrm{w}(\mathrm{Ca})$ as template in the synthesis of the particles leads to an even more heterogeneous sample of irregular acicular particles. Calcination of 2.5SBO-Fe-nAp leads to an increased size heterogeneity with a predominant population of enlarged particles. In all the micrographs relative to Fe-containing samples, it is possible to observe the presence of globular lumps characterized by higher optical density assignable to iron-containing domains of nanometric size $(<10$ $\mathrm{nm}$ ), as also reported for Fe-containing particles obtained by similar synthetic procedures. ${ }^{16,17}$ The lumps are distributed quite homogeneously in the materials, indicating that the synthesis in the presence of $\mathrm{Fe}^{2+} / \mathrm{Fe}^{3+}$ salts brought about a good dispersion of iron-containing phases on Ap-based materials. This characteristic seems to be enhanced in the SBO patterned particles.

The XRD diffractograms of nAp-based materials are shown in Figure 2. Hydroxyapatite XRD patterns are observed in all

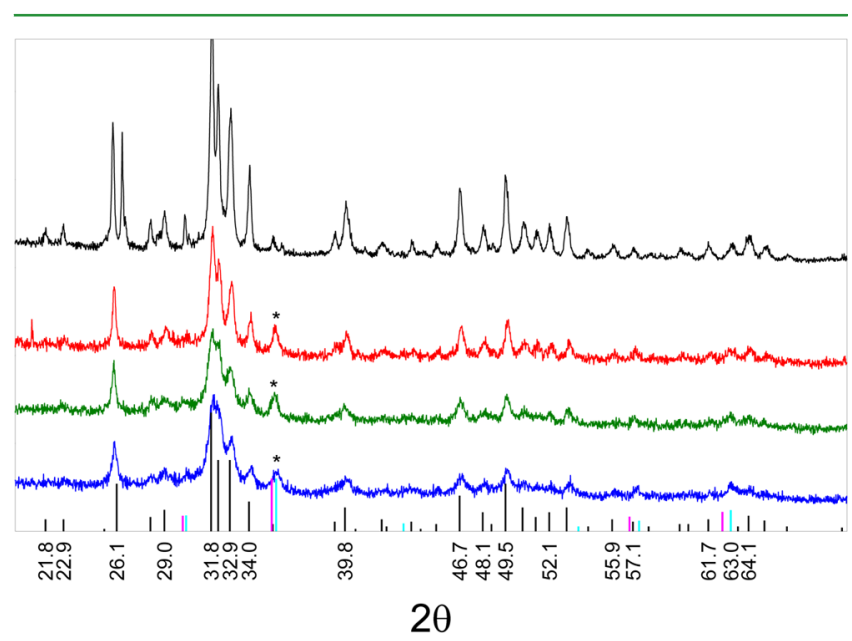

Figure 2. X-ray diffractograms of (from top to down) nAp, Fe-nAp, 2.5SBO-Fe-nAp, and 2.5SBO-Fe-nAp-cal. Bars stand for hydroxyapatite (black), maghemite (cyan), and magnetite (pink) principal reference patterns. Astericks indicate the $2 \theta=35.5$ diffraction peak.

the prepared powders with no significant shifting of peak positions, thus suggesting that $\mathrm{Fe}^{2+} / \mathrm{Fe}^{3+}$ incorporation did not greatly modify the hydroxyapatite structure. A marked broadening increase of the XRD peaks of Fe-nAp, and particularly of 2.5SBO-Fe-nAp and 2.5SBO-Fe-nAp-cal powders, strongly indicates an important reduction in the crytalline structure of the particles. In addition, these samples exhibit more intense diffraction peaks at $2 \theta=35.5$ as well as peaks of lower intensity at $2 \theta=30.2$ and 62.5, characteristic of magnetite and maghemite structures (depicted in Figure 2). Despite the presence of magnetite and maghemite crystalline phases is being supported, they could not be unambigously differentiated, since their XRD diffraction spectrum mainly differ in the relative intensity of the peaks. In fact, the obtained
XRD data closely resembles those reported for Fe-containing hydroxyapatites from different synthetic methods. ${ }^{15,16,21}$

The FTIR spectra of the particles are shown in Figure 3. nAp spectrum shows the fundamental vibration modes of $\mathrm{PO}_{4}$

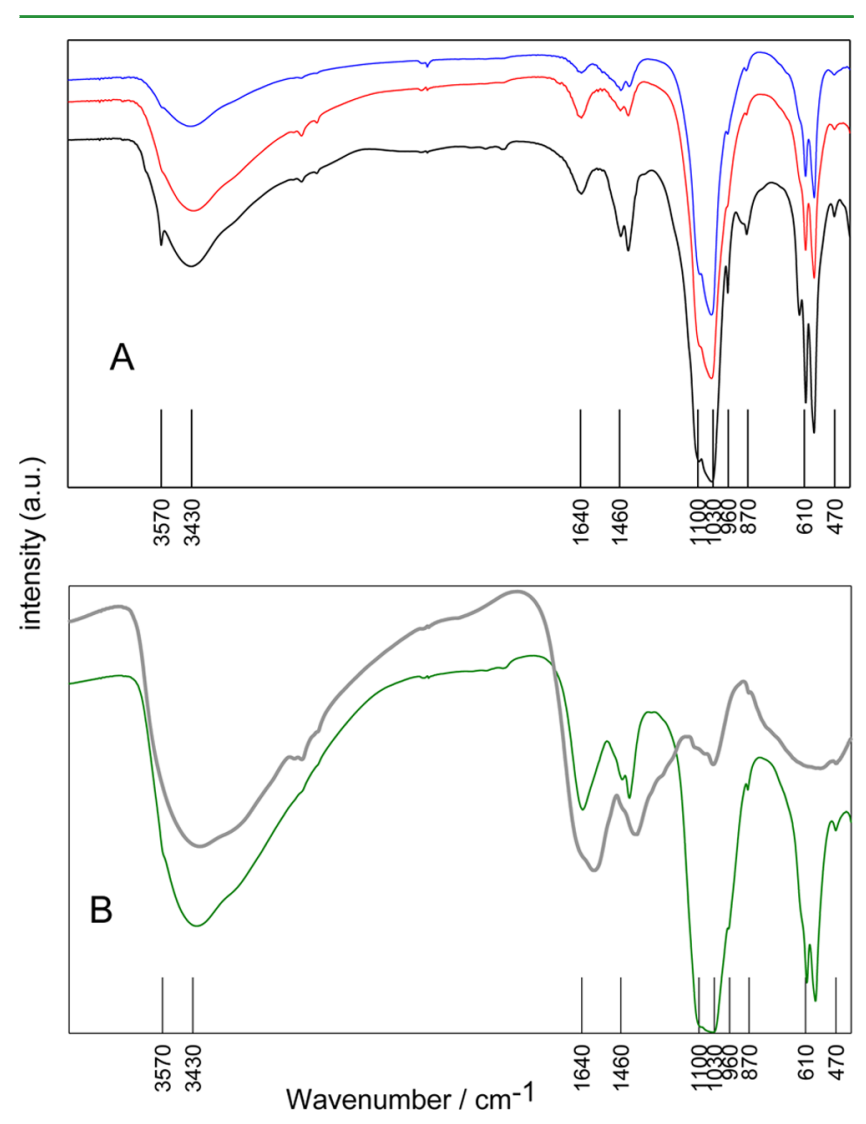

Figure 3. FTIR spectra (from down to top): (A) nAp, Fe-nAp, and 2.5SBO-Fe-nAp-cal. (B) SBO and 2.5SBO-Fe-nAp.

groups of the apatitic structure at about 470, 560, 610, 960, and $1030-1100 \mathrm{~cm}^{-1} .22$ Moreover, the bands at 870 and 1460 $\mathrm{cm}^{-1}$ attributed to residual carbonate from the synthesis process are also observed. The broad bands in the regions 1640 and $3430 \mathrm{~cm}^{-1}$ correspond to $\delta \mathrm{H}-\mathrm{O}-\mathrm{H}$ bands and $\nu \mathrm{OH}$ signals due to $\mathrm{HOH}$ bands of lattice and physisorbed water molecules. The IR spectrum of Fe-nAp shows mainly peaks atributed to nAp. The characteristic peaks due to iron oxides in the 600$400 \mathrm{~cm}^{-1}$ range $^{23}$ may be occluded by those of nAp due to the low amount of iron present in the samples. The $2.5 \mathrm{SBO}-\mathrm{Fe}-$ nAp spectrum shown in Figure $3 \mathrm{~B}$ evidences nAp signals overimposed to those of SBO (also shown in the figure). The intense bands at 3430 and $1649 \mathrm{~cm}^{-1}$ indicate the presence of $\mathrm{HO}$ groups of phenols, alcohols, and carboxyl groups and of $\mathrm{C}=\mathrm{O}$ bonds of carboxyl and carbonyl moieties, respectively. On the other hand, the FTIR absorption peaks of 2.5SBO-Fe$\mathrm{nAp}$-cal may be assigned mainly to those of $\mathrm{nAp}$, thus indicating that $3 \mathrm{~h}$ calcination at $600{ }^{\circ} \mathrm{C}$ of $2.5 \mathrm{SBO}-\mathrm{Fe}-\mathrm{nAp}$ powders is effective in eliminating $\mathrm{SBO}$ residues. $\mathrm{nAp}$ spectrum also shows the sharp hydroxyl bands at 632 and $3572 \mathrm{~cm}^{-1}$, typical of nAp with a high degree of crystallinity. The absence of these peaks in the spectra of all the other particles suggests that the powders show poor crytallinity, in agreement with XRD data also supporting a decreased hydroxyapatite crystallinity upon $\mathrm{Fe}$ addition and use of $\mathrm{SBO}$ as organic template. 
The TGA curves (see Figure 4) obtained in a $\mathrm{N}_{2}$ environment in the temperature range from 80 to $800{ }^{\circ} \mathrm{C}$ for

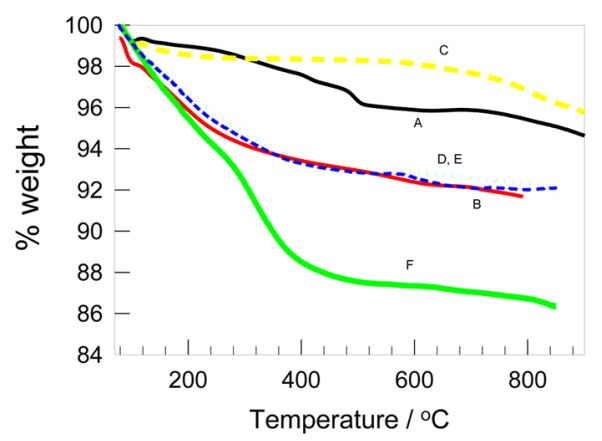

Figure 4. TGA performed in a $\mathrm{N}_{2}$ atmosphere, curves (A) nAp, (B) Fe-nAp, and (C) 2.5SBO-Fe-nAp-cal. TGA performed in an $\mathrm{O}_{2}$ atmosphere, curves (D) 0.05SBO-Fe-nAp, (E) 0.5SBO-Fe-nAp, and (F) 2.5SBO-Fe-nAp. Corresponding derivative curves are shown in $\mathrm{S} 1$.

Ap-based materials yield information on the adsorbed substrates, as decomposition of the Ap structure is expected at temperatures over $900{ }^{\circ} \mathrm{C} .{ }^{22}$ The $5.9 \%$ total mass loss of $\mathrm{nAp}$ is attributed to adsorbed water $\left(T \leq 100{ }^{\circ} \mathrm{C}\right)$, dehydration of hydroxides $\left(380-500{ }^{\circ} \mathrm{C}\right)$, and elimination of surface carbonate-like groups $\left(500-800{ }^{\circ} \mathrm{C}\right)$, in good agreement with literature reports for nano-sized Ap powders. ${ }^{22}$ Fe-nAp shows an $8 \%$ total mass loss between 80 and $800{ }^{\circ} \mathrm{C}$ attributed to adsorbed water, dehydration of $\mathrm{Fe}$ hydroxides $\left(380-500{ }^{\circ} \mathrm{C}\right)$, and elimination of surface carbonate-like groups. On the other hand, 2.5SBO-Fe-nAp powder shows a $14 \%$ total mass loss suggesting an important contribution of SBO pyrolysis (curve not shown), in agreement with the fact that only a $4 \%$ weight loss is observed for the same particles calcined for three hours at $600{ }^{\circ} \mathrm{C}$. The latter observations are in agreement with the FTIR spectra indicating the presence of SBO in 2.5SBO-Fe$\mathrm{nAp}$ and a complete elimination of the organic template in the calcined powders. An estimation of the particles carbon content may be obtained from the mass loss in the temperature range from 200 to $380{ }^{\circ} \mathrm{C}$ observed in TGA curves performed in an $\mathrm{O}_{2}$ environment. Approximately $5 \%$ mass content due to SBO is estimated for $2.5 \mathrm{SBO}-\mathrm{Fe}-\mathrm{nAp}$. TGA curves of $0.5 \mathrm{SBO}-\mathrm{Fe}-$ $\mathrm{nAp}$ and 0.05SBO-Fe-nAp performed in the presence of $\mathrm{O}_{2}$ agree, within the experimental error, with that of $\mathrm{Fe}-\mathrm{nAp}$, indicating that no significant amounts $(<1 \%)$ of organic matter are present in the materials.

Table 1 depicts the specific surface area of the synthetized powders as determined by the BET model and the relative crystallites domain size as estimated by the Scherrer equation using the XRD data. Crystalline nAp shows the lowest surface area, while almost a twofold increase is observed for Fe-nAp, and a further $15 \%$ increase is observed for 2.5SBO-Fe-nAp. Calcination of the latter reduces the surface area by $15 \%$. The $\mathrm{BET}$ isotherms show hysteresis mainly at high $P / P^{0}$ values related to $\mathrm{N}_{2}$ condensation inside interparticle macropores of ca. $100 \mathrm{~nm}$ (see S2). Crystallite domain sizes decrease in the trend $n A p<$ Fe-nAp $<2.5 S B O-F e-n A p$, while a further increase is observed for 2.5SBO-Fe-nAp-cal. All together, the results suggest a reduced crystallite domain size with increasing specific surface area and particle size diminution. The increase of specific surface area besides crystallinity diminution is also reported for nanoparticulated apatite. ${ }^{24}$

The average hydrodynamic particle size distribution determined by DLS measurements, shown in Figure 5,

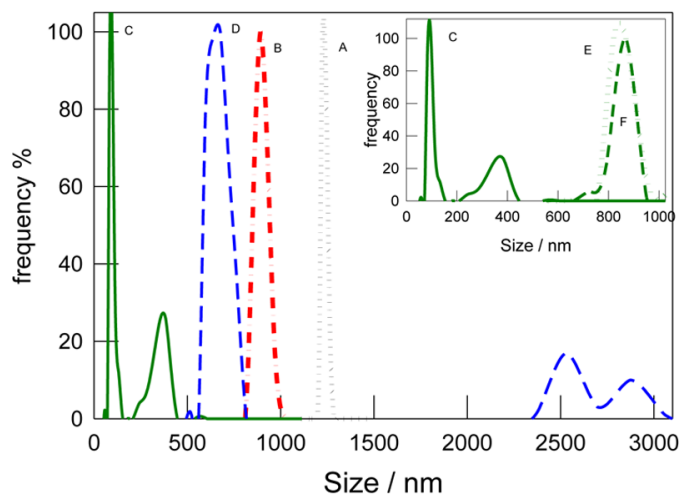

Figure 5. Hydrodynamic particle size distribution as obtained by DLS for nAp (A), Fe-nAp (B), 2.5SBO-Fe-nAp (C), 2.5SBO-Fe-NA-cal (D), 0.5SBO-Fe-nAp (inset, E), and 0.05SBO-Fe-nAp (inset, F).

indicates that the particles hydrodynamic sizes are several fold-times higher than the sizes observed in TEM micrographs. Thus, important aggregation in aqueous solutions at $\mathrm{pH} 7$ and $0.01 \mathrm{M}$ ionic strength takes place. The amount of SBO used as template in the particles synthesis strongly influences aggregation, as smaller hydrodynamic sizes are observed for increasing SBO concentrations. Calcination of 2.5SBO-Fe-nAp particles increases the aggregates size, in line with the population of larger particles depicted in the corresponding HRTEM micrographs (vide supra). Aggregate sizes in the range of $100 \mathrm{~nm}$ are observed for 2.5SBO-Fe-nAp particles, and interparticle macroporosity of almost the same size is evidenced by $\mathrm{N}_{2}$ gas-volumetric adsorption, thus indicating that macropores formed in the solid state do not have real significance in aqueous suspensions of the particles.

Table 1. Specific Surface Area As Obtained from BET Isotherms, Lower Limit Size As Estimated by the Scherrer Equation, Surface Stoichiometric Ratio Obtained by XPS Analysis, \% C from TGA Experiments, Electrophoretic Mobility $(\mu)$ in the pH Range from 6.5 to 7, Bulk Ca and Fe Percentages, and Fe to Ca Molar Ratio in the Particle Bulk

\begin{tabular}{|c|c|c|c|c|c|c|c|c|}
\hline \multirow[b]{2}{*}{ particle type } & \multirow[b]{2}{*}{ specific surface area $/ \mathrm{m}^{2} \mathrm{~g}^{-1}$} & \multirow[b]{2}{*}{$\begin{array}{c}\text { crystallite domain size/ } \\
\mathrm{nm}\end{array}$} & \multirow[b]{2}{*}{$\begin{array}{l}\text { surface } \\
\text { composition }\end{array}$} & \multirow[b]{2}{*}{$\% \mathrm{w} / \mathrm{w} \mathrm{SBO}$} & \multirow[b]{2}{*}{$\begin{array}{c}\mu \\
(\mathrm{mS} / \mathrm{cm})\end{array}$} & \multicolumn{3}{|c|}{ bulk } \\
\hline & & & & & & $\% \mathrm{Ca} \mathrm{w} / \mathrm{w}$ & $\% \mathrm{Fe} \mathrm{w} / \mathrm{w}$ & $\begin{array}{c}\mathrm{Fe} / \\
\mathrm{Ca}\end{array}$ \\
\hline nAp & 34 & $30-50$ & $\mathrm{Ca}_{1} \mathrm{P}_{0.7} \mathrm{O}_{3.1} \mathrm{Fe}_{0}$ & 0 & +0.95 & 38.4 & $<0.02$ & 0 \\
\hline Fe-nAp & 64 & $20-40$ & $\mathrm{Ca}_{1} \mathrm{P}_{09} \mathrm{O}_{46} \mathrm{Fe}_{014}$ & 0 & -1.8 & 28.4 & 7.8 & 0.2 \\
\hline 0.05SBO-Fe-nAp & 68 & ---- & --- & $<1$ & -1.5 & 31.2 & 7.4 & 0.17 \\
\hline $0.5 \mathrm{SBO}-\mathrm{Fe}-\mathrm{nAp}$ & 70 & ---- & $\mathrm{Ca}_{1} \mathrm{P}_{0.7} \mathrm{O}_{3.7} \mathrm{Fe}_{0.09}$ & $<1$ & -1.6 & 29.0 & 6.9 & 0.17 \\
\hline 2.5SBO-Fe-nAp & 71 & $10-30$ & $\mathrm{Ca}_{1} \mathrm{P}_{075} \mathrm{O}_{37} \mathrm{Fe}_{0.09}$ & $\sim 5$ & -1.8 & 28.3 & 6.6 & 0.17 \\
\hline 2.5SBO-Fe-nAp-cal & 64 & $20-60$ & $\mathrm{Ca}_{1} \mathrm{P}_{0.8} \mathrm{O}_{3.3} \mathrm{Fe}_{0.06}$ & 0 & ----- & 30.9 & 7.2 & 0.17 \\
\hline
\end{tabular}


The electrophoretic mobility of the particles obtained in the $\mathrm{pH}$ range from 6.5 to 7 is depicted in Table 1. nAp and Fe-nAp values of +0.95 and $-1.8 \mathrm{mS} / \mathrm{cm}$, respectively, indicate that the incorporation of $20 \% \mathrm{Fe}$ on the hydroxyapatite particles brings about an increased surface charge density and a predominance of negative surface charges. Moreover, SBO-patterned particles show electrophoretic mobilities similar to those observed for Fe-nAp. The contrast between the similar mobilities of these particles with their different aggregates size strongly suggests an increased surface hydrophylicity in SBO-patterned particles due to the presence of uncharged surface groups which strongly stabilize the aqueous suspensions of the particles.

The XPS survey spectra of the particles (see S4) depict the main lines for $\mathrm{Ca}, \mathrm{O}, \mathrm{P}$, and $\mathrm{Fe}$ (except for $\mathrm{nAp}$ ). Beside these peaks, a C(1s) "adventitious carbon" peak was observed which was used for binding energy correction due to charging effects by setting it to $284.6 \mathrm{eV}$. Carbonate-type carbon, incorporated during synthesis, was also observed. All powders show the $\mathrm{Ca} 2 \mathrm{p} 1 / 2(350.8 \mathrm{eV})$ and $\mathrm{Ca} 2 \mathrm{p} 3 / 2(347.4 \mathrm{eV})$ lines, and the $\mathrm{P} 2 \mathrm{~s}$ line at $191 \mathrm{eV}$ due to calcium phosphate in apatite (see S5). On the other hand, analysis of $\mathrm{Fe} 2 \mathrm{p} 3 / 2$ peaks is more controversial. The use of broad peak shapes has proved useful for the identification of pure compounds but of lesser use for the identification of mixtures due to the spectral overlap of most $\mathrm{Fe}$ (III) compounds which show similar binding energies but varying peak shapes and satellite intensities. ${ }^{25}$ In fact, such analysis leads to a peak at about $710.5 \mathrm{eV}$ with a satellite displaced $4 \mathrm{eV}$ and a second broad peak at about $712.5 \mathrm{eV}$ with no satellite contribution unless overlapped to the Fe2p1/2 portion of the spectrum. These peaks did not match the reported data of neither pure $\mathrm{Fe}$ oxides ${ }^{26}$ nor of phosphated iron. ${ }^{27}$ Therefore, Fe2p3/2 peaks for all the iron-containing samples herein synthesized were modelled using a combination of ferrous and ferric multiplet patterns for the lower and higher energy portion of the spectrum, respectively, ${ }^{25,28}$ as shown in Figure 6 for Fe-nAp. Fe2p3/2 signal adjustment was performed

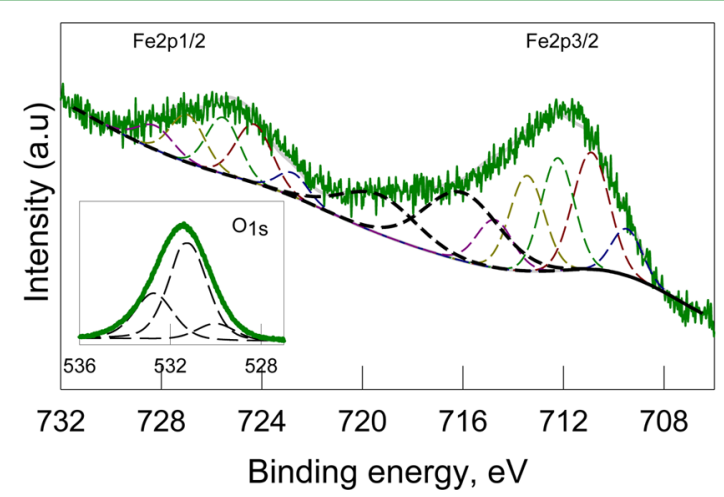

Figure 6. XPS Fe2p3/2 and Fe2p1/2 signals (full line) for 2.5SBO-Fe$\mathrm{nAp}$ and contributing peaks (dashed lines). Inset: O1s signals (full line) and contributing species (dashed lines).

assuming a Shirley type baseline and using the lowest number of peaks allowed with about $1.7 \mathrm{eV}$ FWHM, except for the peak attributed to the Fe II satellite which was left free. All samples show contributing peaks at 709.5, 710.9, 712.2, 713.4, 714.9 eV, and $\mathrm{Fe}^{2+}$ satellite peak shifted by $4.8-5 \mathrm{eV}$, in line with the patterns reported for $\mathrm{Fe}(\mathrm{II})-\mathrm{PO}_{4}$ surface oxidized to $\mathrm{Fe}(\mathrm{III})-$ $\mathrm{OH}^{28}$ Moreover, no metallic component can be observed in the spectrum indicating its absence in the surface layer. The observed satellite peak at ca. $719 \mathrm{eV}$, may be assigned to the contribution of iron oxides. ${ }^{26,29}$ Observed Fe2p3/2 and Fe2p1/ 2 signals separations, $\Delta E$ (BE $2 \mathrm{p} 3 / 2-\mathrm{BE} 2 \mathrm{p} 1 / 2)$, of about $13.0-13.3 \mathrm{eV}$ are in agreement with reported data for Fe oxides and salts. ${ }^{26}$ Therefore, the XPS data points to a complex mixture of $\mathrm{Fe}^{2+} / \mathrm{Fe}^{3+}$ phosphates and oxides on the particles surface.

Deconvolution of the O1s peak of n-Ap shows the main contribution of a band at $531.8 \mathrm{eV}(96 \%)$ and a minor contribution at $532.8 \mathrm{eV}$. According to literature reports, these peaks may be assigned to oxygen atoms in phosphates and hydroxyls and to adsorbed water, respectively, in agreement with reported data for hydroxyapatite. ${ }^{27}$ On the other hand, $\mathrm{O} 1 \mathrm{~s}$ peaks of $\mathrm{Fe}$-containing particles are best modelled when the contribution of a third peak at ca. $530.1 \mathrm{eV}$ characteristic of $\mathrm{O}$ atoms in iron oxide environments is considered, ${ }^{26}$ as depicted in Figure 6 inset and S5. Peak contributions of 22\% and $13 \%$ were observed for Fe-nAp and 2.5SBO-Fe-nAp-cal, respectively, while contributions of ca. $5 \%$ were observed for 0.5SBO-Fe-nAp and 2.5SBO-Fe-nAp. The latter observations are in line with the larger peak area of $\mathrm{Fe} 2 \mathrm{p} 3 / 2$ multiplets of $\mathrm{BE}$ $>711 \mathrm{eV}$ observed for Fe-nAp and 2.5SBO-Fe-nAp-cal, normally identified with $\mathrm{Fe}^{3+}$ ions.

Considering the experimental sensitivity factors relative to the different elements, a surface $\mathrm{Ca}: \mathrm{P}: \mathrm{O}$ stoichiometric ratio was determined for each particle type as depicted in Table 1 . The $\mathrm{P} / \mathrm{Ca}$ ratio for $\mathrm{nAp}$ is somewhat higher than the expected theoretical $\mathrm{Ca}\left(\mathrm{PO}_{4}\right)_{0.6} \mathrm{O}_{0.2}$ stoichiometric ratio but close to the values reported in the literature for several hydroxyapatite materials and attributed to the presence of surface acid phosphates. ${ }^{29}$ On the other hand, the $\mathrm{O} / \mathrm{P}$ ratio is, within the experimental error, in line with the expected value for hydroxyapatite. Fe-nAp shows higher $\mathrm{P} / \mathrm{Ca}$ and $\mathrm{O} / \mathrm{Ca}$ ratios than nAp. All together, the data seems to indicate that surface iron increases phosphate content due to the formation of $\mathrm{Fe}(\mathrm{II})$-phosphates, while surface $\mathrm{Fe}^{3+}$ seems to lead to the formation of iron oxides. In fact, $\mathrm{Fe}$ (III)-substituted hydroxyapatite nanoparticles were reported to show an increased surface hydrophilicity as a consequence of the formation of surface $\mathrm{Fe}-\mathrm{OH}$ groups, though the number of original $\mathrm{Ca}(\mathrm{II})$ atoms was reduced. ${ }^{19}$

On the other hand, lower $\mathrm{Fe} / \mathrm{Ca}$ surface ratios were observed when SBO was used as a template in the particle synthesis. 0.5SBO-Fe-nAp and 2.5SBO-Fe-nAp show $\mathrm{P} / \mathrm{Ca}$ ratios similar to those of $\mathrm{nAp}$, though the respective $\mathrm{O} / \mathrm{Ca}$ ratios are significantly higher, thus suggesting the presence of surface $\mathrm{OH}$ groups. Upon calcination, 2.5SBO-Fe-nAp show a decreased content in surface oxygen and iron.

Hysteretic $\mathrm{M}-\mathrm{H}$ curves of Fe-nAp and 2.5SBO-Fe-nAp at $300 \mathrm{~K}$ (see S3) exhibit a superparamagnetic behavior with zero coercivity and zero remanence on the magnetization curves. For both particles, the saturation magnetization was of $4 \mathrm{emu} / \mathrm{g}$ of particles, in line with reported values for Fe-nAp nanopowders. ${ }^{15,16}$ Considering a $7 \% \mathrm{w} / \mathrm{w}$ iron content in the particles (see Table 1), the saturation magnetization per gram of iron is $57 \mathrm{emu} / \mathrm{g} \mathrm{Fe}$, half the value expected for magnetite nanoparticles. ${ }^{30}$ Therefore, formation of significant amounts of iron compounds not contributing to the overall paramagnetism is supported.

The described results clearly indicate that introduction of $\mathrm{Fe}^{3+} / \mathrm{Fe}^{2+}$ ions and the use of $\mathrm{SBO}-\mathrm{Ca}^{2+}$ complexes as templates during hydroxyapatite synthesis leads to a diminution in the apatite crystalline structure, a negatively charged surface, and an increased surface hydrophilicity. Formation of magnetite 
and/or maghemite is observed by XRD. However, iron oxides formation is not the only fate of iron. The loss of crystallinity of the apatite structure might be a consequence of $\mathrm{Ca}^{2+}$ exchange by $\mathrm{Fe}^{2+} / \mathrm{Fe}^{3+}$ ions. In fact, XPS analysis clearly indicates the presence of surface $\mathrm{Fe}^{2+}$ phosphates salts and oxidized $\mathrm{Fe}^{3+}$. Formation of surface $\mathrm{FeO}$ and $\mathrm{OH}$ groups is suggested from the $\mathrm{O} 2 \mathrm{~s}$ peak analysis. A comparison between Fe:Ca contents in the particles volume and at the surface, see Table 1, indicates that $\mathrm{Fe}$ ions are preferentially incorporated in the particles core.

Metal Adsorption Capacity. Figure 7 shows the measured $\mathrm{Cu}^{2+}$ adsorption isotherms. The one-adsorption site Langmuir

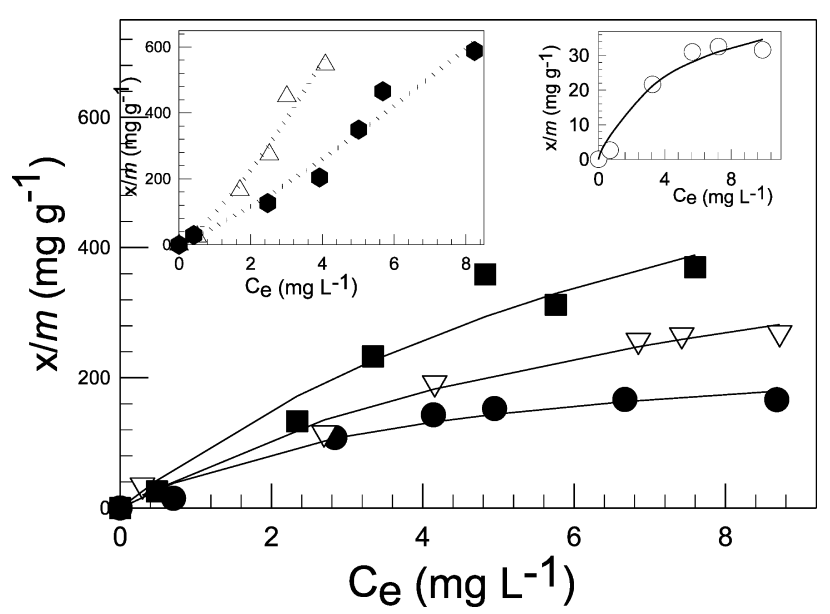

Figure 7. $\mathrm{Cu}^{2+}$ adsorption isotherms at $25{ }^{\circ} \mathrm{C}$. Main figure: Fe-nAp

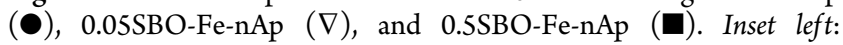
2.5SBO-Fe-nAp $(\Delta)$ and 2.5SBO-Fe-nAp-cal ( ). Inset right: nAp $(O)$. The solid lines and dashed lines stand to the fitting of the data to eqs 1 and 2, respectively.

model, eq 1 , fits the isotherms of $\mathrm{Cu}^{2+}$ adsorption on nAp, Fe$\mathrm{nAp}, 0.05 \mathrm{SBO}-\mathrm{Fe}-\mathrm{nAp}$, and 0.5SBO-Fe-nAp with regression coefficients $r^{2}>0.95$. The obtained fitting parameters are depicted in Table 2 . The affinity coefficient of $\mathrm{Cu}^{2+}$ adsorption, $k_{\mathrm{L}}$, shows the trend $\mathrm{nAp} \approx \mathrm{Fe}-\mathrm{nAp}>0.05$ SBO-Fe-nAp $\approx$ $0.5 \mathrm{SBO}-\mathrm{Fe}-\mathrm{nAp}$, while the maximum number of sites $b$ increases in the order nAp $<$ Fe-nAp $<0.05$ SBO-Fe-nAp < $0.5 \mathrm{SBO}-\mathrm{Fe}-\mathrm{nAp}$. On the other hand, adsorption on 2.5SBO-FenAp and 2.5SBO-Fe-nAp-cal particles were better fitted by the Freundlich model, eq 2 . This experimental isotherm has been interpreted to arise from an heterogeneous surface showing a distribution of different adsorption sites, where $1 / n \leq 1$ is an experimentally determined exponent and $k_{\mathrm{F}}$ is the Freundlich constant. However, within the experimental error, obtained values of $n$ are close to 1 , thus suggesting the applicability of the Langmuir isotherm under the condition $1 \gg k_{\mathrm{L}} \times C_{\mathrm{e}}$ and $k_{\mathrm{F}}=$ $k_{\mathrm{L}} \times b$. In fact, the maximum $\mathrm{Cu}^{2+}$ absorption could not be reached for these particles due to the limited $\mathrm{Cu}^{2+}$ solubility. ${ }^{18}$ Taking $k_{\mathrm{L}} \times b=90 \mathrm{mg} \mathrm{g}^{-1}$ for 2.5SBO-Fe-nAp and considering $k_{\mathrm{L}} \approx 0.11$ for SBO-templated particles (vide supra), results in $b$ $\approx 850 \pm 400 \mathrm{mg} \mathrm{g}^{-1}$.

$$
\begin{aligned}
& x / m=\frac{k_{\mathrm{L}} \times b \times C_{\mathrm{e}}}{1+k_{\mathrm{L}} \times C_{\mathrm{e}}} \\
& x / m=k_{\mathrm{F}} \times C_{\mathrm{e}}^{1 / n}
\end{aligned}
$$

Isolation of the $\mathrm{Cu}^{2+}$-adsorbed $\mathrm{nAp}, \mathrm{Fe}-\mathrm{nAp}$, and 0.5SBO-Fe$\mathrm{nAp}$ and further resuspension in an aqueous solution of $\mathrm{pH} 7$ show $0.2,0.1$, and $0.02 \% \mathrm{Cu}^{2+}$ leaching after two hours, respectively. Thus indicating that $\mathrm{Cu}^{2+}$ is strongly chemisorbed at $\mathrm{pH} 7$.

The obtained value of $b$ for $\mathrm{nAp}$ is in line with that reported for $\mathrm{Cu}^{2+}$ adsorption on commercial nanohydroxyapatite at $\mathrm{pH}$ $7.2\left(64.8 \mathrm{mg} \mathrm{g}^{-1}\right)$, though the reported ${ }^{2} k_{\mathrm{L}}=0.80$ is almost 4 times higher than that found here. An even number of regularly spaced, positively charged, calcium ions and negatively charged oxygen groups on the surface of crystalline Ap support metal cation retention due to ion exchange and/or coordination with $\mathrm{P}$-sites and surface $\mathrm{HO}$. Moreover, $\mathrm{Cu}^{2+}$ precipitation with free $\mathrm{PO}_{4}{ }^{3-}$ ions as a consequence of the high Ap solubility at $\mathrm{pH} 5$ is also reported. ${ }^{31}$ In our experiments, the amounts of calcium and iron ion concentrations measured in solution during the $\mathrm{Cu}^{2+}$ adsorption experiments are ca. 17 and $0.5 \mu \mathrm{g} / \mathrm{g} \mathrm{NP}$, respectively, for all the particles, independently of the adsorbed amount of $\mathrm{Cu}^{2+}$ ions. Therefore, $\mathrm{Cu}^{2+}$ exchange for $\mathrm{Ca}^{2+}$ and $\mathrm{Fe}^{2+}$ in the hydroxyapatite structure seems not to significantly contribute to $\mathrm{Cu}^{2+}$ adsorption under our experimental conditions.

Moreover, the observed increase in the specific surface area of Fe-nAp and SBO-Fe-nAp containing particles seems not to be the cause of the increased $\mathrm{Cu}^{2+}$ adsorption of these materials (vide infra), as normalization of the adsorption isotherms by the specific surface area of the materials does not modify the observed trend.

Reported $\mathrm{Cu}^{2+}$ maximum adsorption capacities for different magnetite composites are of the order of 1.9 for aqueous suspensions of $\mathrm{pH} 5.5,^{32} 56.71$ for magnetite-immobilized chitin, $^{33}$ and $140-150 \mathrm{mg} / \mathrm{g}$ for magnetite-immobilized pseudomonas putida $5 \mathrm{X}$ cells at $\mathrm{pH} 7 .^{32}$ These values are below those observed for the materials herein synthesized. On the other hand, $\mathrm{Cu}^{2+}$ ions have been reported to readily form nonlabile complexes with fulvic acids and dissolved natural organic matter, $\mathrm{DOM}^{34}$ as amino groups, phenolic hydroxyls, and adjacent aromatic carboxylates provide lone pairs of electrons for chelating $\mathrm{Cu}^{2+}$ ions. The reported total number of binding sites range from 1 to $100 \mu \mathrm{M} \mathrm{mg} \mathrm{C}^{-1}$ depending on $\mathrm{pH}$, ionic strength, and the DOM origin and concentration. A rough estimation of the adsorption sites provided by SBO may be

Table 2. Fitting Parameter Values of the Langmuir and Freundlich Models ${ }^{a}$

\begin{tabular}{lllllr}
\multicolumn{1}{c}{ particle } & eq & $b / \mathrm{mg} \mathrm{g}^{-1}$ & $k_{\mathrm{L}}$ & $1 / n$ & $k_{\mathrm{F}} / \mathrm{mg} \mathrm{g}^{-1}$ \\
nAp & 1 & $50(25)$ & $0.22(0.1)$ & & 0.967 \\
Fe-nAp & 1 & $265(60)$ & $0.24(0.02)$ & & 0.969 \\
0.05SBO-Fe-npA & 1 & $550(200)$ & $0.12(0.04)$ & & 0.978 \\
0.5SBO-Fe-nAp & 1 & $850(400)$ & $0.10(0.07)$ & & 0.953 \\
2.5SBO-Fe-nAp & 2 & & & $1.3(0.2)$ & $90(22)$ \\
2.5SBO-Fe-nAp-cal & 2 & & & $1.2(0.2)$ & $50(15)$
\end{tabular}

${ }^{a}$ Error bars are denoted in parentheses. 
obtained if it is considered that $5 \%$ mass of $2.5 \mathrm{SBO}-\mathrm{Fe}-\mathrm{nAp}$ is due to SBO organic residues, from which $38.5 \%$ in weight is due to $\mathrm{C}$ atoms. Therefore, taking the maximum amount of 100 $\mu \mathrm{M}$ sites $\mathrm{mg} \mathrm{C}^{-1}, \sim 122 \mathrm{mg} \mathrm{g}^{-1} \mathrm{Cu}^{2+}$ ions would be adsorbed by the organic matter, well below the obtained values (see Table 2 ). Consequently, the increased $\mathrm{Cu}^{2+}$ adsorption capacity observed for SBO-patterned particles cannot be assigned solely to surface-trapped SBO, neither to the small magnetite domains observed on the particles surface. These observations are further supported by the significant $\mathrm{Cu}^{2+}$ adsorption capacity still observed for 2.5SBO-Fe-nAp-cal despite the elimination of all $\mathrm{C}$-containing residues due to calcination.

As discussed above, the main differences observed between $\mathrm{nAp}$ and Fe-containing apatites involve a reduction in the crystallinity of hydroxyapatite domains, a reduced $\mathrm{Ca}^{2+}$ content, and the formation of surface phosphated iron and magnetite/ maghemite phases. An increased O-content is also observed at the surface of all SBO-Fe-nAp materials. Such surface and structural modifications might support an increased adsorption efficiency of the iron-containing hydroxyapatite materials due to $\mathrm{Cu}^{2+}$ complexation with surface $\mathrm{PO}_{4}$ and $\mathrm{OH}$ groups. It results striking though, that despite both $0.5 \mathrm{SBO}-\mathrm{Fe}-\mathrm{nAp}$ and $2.5 \mathrm{SBO}-$ Fe-nAp showing similar surface composition, except for the small $\mathrm{C}$ content of the latter, $\mathrm{Cu}^{2+}$ adsorption ability of 2.5SBO-Fe-nAp is significantly higher. We suggest, therefore, that the smaller aggregates formed by $2.5 \mathrm{SBO}-\mathrm{Fe}-\mathrm{nAp}$ in aqueous suspensions makes the particles surface more available for $\mathrm{Cu}^{2+}$ adsorption. In fact, strong electrostatic interactions might prevent $\mathrm{Cu}^{2+}$ ions to approach the binding sites of the particles surface within the aggregates. Surface area measurements of dry materials do not necessarily represent the effective surface area of suspended particles in aqueous solution because of the particles agglomeration in suspension. ${ }^{35,36}$

A rough estimation of the effective surface area may be obtained if it is assumed that $\mathrm{Cu}^{2+}$ is mainly adsorbed at the agglomerates surface and taking the agglomerates hydrodynamic radius distribution measured by DLS and the density value of hydroxyapatite $\left(3.156 \mathrm{~g} / \mathrm{cm}^{3}\right)^{37}$ for all the particles. Normalization of the isotherms shown in Figure 6 by the estimated effective agglomerate area $(1.55,2.1,2.2,2.3,6.5$, and $2.8 \mathrm{~m}^{2} \mathrm{~g}^{-1}$ for $\mathrm{nAp}, \mathrm{Fe}-\mathrm{nAp}, 0.05 \mathrm{SBO}-\mathrm{Fe}-\mathrm{nAp}, 0.5 \mathrm{SBO}-\mathrm{Fe}-\mathrm{nAp}$, 2.5SBO-Fe-nAp, and 2.5SBO-Fe-nAp-cal, respectively) yields adsorption isotherms (see Figure 8) which may be classified in two main groups: nAp and Fe-containing apatites. Iron-

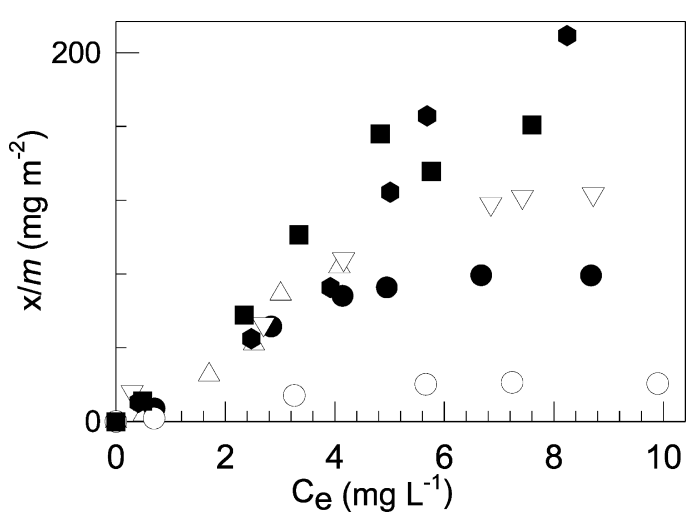

Figure 8. $\mathrm{Cu}^{2+}$ adsorption isotherms at $25{ }^{\circ} \mathrm{C}$ normalized by the effective area (see text). nAp (O), Fe-nAp $(\bullet), 0.05 S B O-F e-n A p(\nabla)$, $0.5 S B O-F e-n A p(\square)$, 2.5SBO-Fe-nAp $(\Delta)$, and 2.5SBO-Fe-nAp-cal (a). containing particles, all depicting similar $k_{\mathrm{L}}$ values, show improved adsorption capacity with respect to pure $n A p$, in line with their described surface characteristics, vide supra. Differences among the adsorption isotherms of the iron-containing particles are mainly observed at high $\mathrm{Cu}^{2+}$ loadings, probably due to $\mathrm{Cu}^{2+}$ adsorption on the particles surface facing the interior of the agglomerates at higher concentrations, a situation not considered in the simplified estimation of the effective surface area.

\section{CONCLUSIONS}

The present results strongly indicate that hydroxyapatite nanoparticles doped with iron and synthetized using SBO as template show significant changes in the particles morphology and surface chemistry. Among the observed effects are the following: a reduction in the crystallinity of hydroxyapatite domains, elongated and smaller particles with higher specific surface area, reduced $\mathrm{Ca}^{2+}$ content, formation of surface phosphated iron and iron oxides, increased oxygen content at the surface, and an overall negative surface charge at $\mathrm{pH}$ 7.0. Moreover, formation of magnetite oxide seems responsible for the particle paramagnetism. Such surface and structural modifications support the formation of stable homogeneous aqueous suspensions of the particles, which show a reduction in the size of the agglomerates when increasing the SBO content in the synthesis procedure.

A significant improvement in the $\mathrm{Cu}^{2+}$ adsorption capacity was observed upon iron-doping of the hydroxyapatite particles and, particularly, for the SBO-templated particles. Such improvement is correlated with a negatively-charged surface and the presence of phosphate and $\mathrm{Fe}-\mathrm{OH}$ surface groups. However, a second important effect appears to be the agglomerates size, as agglomeration seems to severely reduce the effective surface available for adsorption in aqueous suspensions.

The materials herein synthetized are a potential, selfsustaining, environmentally friendly, and efficient material for $\mathrm{Cu}^{2+}$ remediation in aqueous effluents. Future work involves metal sorption selectivity studies and metal desorption conditions for particle reuse.

\section{ASSOCIATED CONTENT}

\section{S Supporting Information}

TGA derivatives, $\mathrm{N}_{2}$ adsorption isotherms and BJH mesoporosity analyses, magnetization curves, XPS survey spectra, and elements high resolution peaks. This material is available free of charge via the Internet at http://pubs.acs.org.

\section{AUTHOR INFORMATION}

\section{Corresponding Author}

*E-mail: gonzalez@inifta.unlp.edu.ar.

\section{Present Address}

\#(E.M.) STAR*Integrated Research Unit, University of Foggia Via Gramsci, 89-91, 71121 Foggia, Italy.

Notes

The authors declare no competing financial interest.

\section{ACKNOWLEDGMENTS}

D.F.M. thanks Consejo Nacional de Investigaciones Cientificas y Técnicas (CONICET, Argentina) for a graduate studentship. M.C.G. is a research member of CONICET. The work was performed partly with funds of the Ministero Italiano delle 
Politiche Agricole within the Agrienergia project and by the grant PIP 112-200801-00356 from CONICET, Argentina. Financial support for academic interchange by the European Union (IRSES-GA-2010-269128, EnvironBOS) is acknowledged. The authors are grateful to the following private and/or public Italian institutions: (a) AceaPinerolese Spa in Pinerolo (TO) for supplying the SBO sourcing biowastes; (b) Studio Chiono and Associati in Rivarolo Canavese (TO) for making available pilot equipment and services for the production of SBO. Beatriz Soria and Simona Sapino are acknowledged for the TGA in the presence of molecular oxygen and DLS measurements, respectively.

\section{REFERENCES}

(1) Moreno, J. C.; Gómez, R.; Giraldo, L. Removal of Mn, Fe, Ni and $\mathrm{Cu}$ Ions from Wastewater Using Cow Bone Charcoal. Materials 2010, 3, 452-466.

(2) Wang, Y.; Zhou, D.; Cui, Y.; Wang, S.; Chen, Y. Adsorption and Desorption of $\mathrm{Cu}(\mathrm{II}), \mathrm{Zn}(\mathrm{II}), \mathrm{Pb}(\mathrm{II})$, and $\mathrm{Cd}(\mathrm{II})$ on the Soils Amended with Nanoscale Hydroxyapatite. Environ. Prog. Sustainable Energy 2010, 29, 233-241.

(3) Lee, Y.; Elzinga, E. J.; Reeder, R. Sorption Mechanisms of Zinc on Hydroxyapatite: Systematic Uptake Studies and EXAFS Spectroscopy Analysis. J. Environ. Sci. Technol. 2005, 39, 4042-4048.

(4) Handley-Sidhu, S.; Renshaw, J. C.; Moriyama, S.; Stolpe, B.; Mennan, C.; Bagherias, S.; Yong, P.; Stamboulis, A.; Paterson-Beedle, M.; Sasaki, K.; Pattrick, R. A.; Lead, D. J. R.; Macaskie, L. E. Uptake of $\mathrm{Sr}^{2+}$ and $\mathrm{Co}^{2+}$ into Biogenic Hydroxyapatite: Implications for Biomineral Ion Exchange Synthesis. Environ. Sci. Technol. 2011, 45, 6985-6990.

(5) Shekhar, N.; Krishanu, B.; Bikramjit, B. Phase Stability and Microstructure Development in Hydroxyapatite-Mullite System. Scr. Mater. 2008, 58, 1054-1057.

(6) Wang, D.; Paradelo, M.; Bradford, S. A.; Peijnenburg, W. J. G. M.; Chu, L.; Zhou, D. Facilitated Transport of Cu with Hydroxyapatite Nanoparticles in Saturated Sand: Effects of Solution Ionic Strength and Composition. Water Res. 2011, 45, 5905-5915.

(7) Pagenkopf, G.; Whitworth, C. Precipitation of Metal-Humate Complexes. J. Inorg. Nucl. Chem. 1981, 43, 1219-1222.

(8) Baigorri, R.; Urrutia, O.; Erro, J.; Mandado, M.; Perez-Juste, I.; Garcia-Mina, J. M. Structural Characterization of Anion-CalciumHumate Complexes in Phosphate-Based Fertilizers. ChemSusChem 2013, 6, 1245-1251.

(9) Boffa, V.; Perrone, D. G.; Montoneri, E.; Magnacca, G.; Bertinetti, L.; Garlasco, L.; Mendichi, R. A Waste Derived Biosurfactant for the Preparation of Templated Silica Powders. ChemSusChem 2010, 3, 445-452.

(10) Kithva, P. H.; Grøndahl, L.; Kumar, R.; Martin, D.; Trau, M. An Organic Matrix-Mediated Processing Methodology to Fabricate Hydroxyapatite Based Nanostructured Biocomposites. Nanoscale 2009, 1, 229-232.

(11) Qu, X.; Alvarez, P. J. J.; Li, Q. Applications of Nanotechnology in Water and Wastewater Treatment. Water Res. 2013, 47, 3931-3946.

(12) Iwasaki, T.; Nakatsuka, R.; Murase, K.; Takata, H.; Nakamura, H.; Watano, S. Simple and Rapid Synthesis of Magnetite/ Hydroxyapatite Composites for Hyperthermia Treatments Via a Mechanochemical Route. Int. J. Mol. Sci. 2013, 14, 9365-9378.

(13) Montoneri, E.; Boffa, V.; Savarino, P.; Perrone, D.; Ghezzo, M.; Montoneri, C.; Mendichi, R. Acid Soluble Bio-Organic Substances Isolated from Urban Bio-Waste. Chemical Composition and Properties of Products. Waste Manage. 2011, 31, 10-7.

(14) Christl, I. Ionic Strength- and pH-Dependence of Calcium Binding by Terrestrial Humic Acids. Environ. Chem. 2012, 9, 89-96.

(15) Tampieri, A.; D’Alessandro, T.; Sandri, M.; Sprio, S.; Bertinetti, L.; Panseri, S.; Pepponi, G.; Goettlicher, J.; Bañobre-López, M.; Rivas, J. Intrinsic Magnetism and Hyperthermia in Bioactive Fe-Doped Hydroxyapatite. Acta Biomater. 2012, 8, 843-851.
(16) Panseri, S.; Cunha, C.; D’Alessandro, T.; Sandri, M.; Giavaresi, G.; Marcacci, M.; Hung, C.; Tampieri, A. Intrinsically Superparamagnetic Fe-Hydroxyapatite Nanoparticles Positively Influence Osteoblast-like Cell Behaviour. J. Nanobiotechnol. 2012, 10, 32.

(17) Patterson, A. The Scherrer Formula for X-ray Particle Size Determination. Phys. Rev. 1939, 56, 978-982.

(18) Hidmi, L.; Edwards, M. Role of Temperature and $\mathrm{pH}$ in $\mathrm{Cu}(\mathrm{OH})_{2}$ Solubility. Environ. Sci. Technol. 1999, 33, 2607-2610.

(19) Kandori, K.; Toshima, S.; Wakamura, M.; Fukusumi, M.; Morisada, Y. Effects of Modification of Calcium Hydroxyapatites by Trivalent Metal Ions on the Protein Adsorption Behavior. J. Phys. Chem. B 2010, 114, 2399-2404.

(20) Morrissey, R.; Rodríguez-Lorenzo, L. M.; Gross, K. A. Influence of Ferrous Iron Incorporation on the Structure of Hydroxyapatite. J. Mater. Sci.: Mater. Med. 2005, 16, 387-392.

(21) Li, Y.; Nam, C. T.; Ooi, C. P. Iron(III) and Manganese(II) Substituted Hydroxyapatite Nanoparticles: Characterization and Cytotoxicity Analysis. J. Phys.: Conf. Ser. 2009, 187, 012024.

(22) Cotescu, A.; Pasuk, I.; Ungureanu, F.; Dinischiotu, A.; Costache, M.; Huneau, F.; Galaup, S.; Le Coustumer, P.; Predoi, D. PhysicoChemical Properties of Nano-Sized Hexagonal Hydroxyapatite Powder Synthesized by Sol-Gel. Dig. J. Nanomater. Bios. 2010, 5, 989-1000.

(23) Li, Y. S.; Church, J. S.; Woodhead, A. L. Infrared and Raman Spectroscopic Studies on Iron Oxide Magnetic Nanoparticles and Their Surface Modifications. J. Magn. Magn. Mater. 2012, 324, 15431550.

(24) Lee, W.-H.; Loo, C.-Y.; Van, K. L.; Zavgorodniy, A. V.; Rohanizadeh, R. Modulating Protein Adsorption onto Hydroxyapatite Particles Using Different Amino Acid Treatments. J. R. Soc., Interface 2012, 9, 918-927.

(25) Biesinger, M. C.; Payne, B. P.; Grosvenor, A. P.; Laua, L. W. M.; Gerson, A. R.; Smart, R. St. C. Resolving Surface Chemical States in XPS Analysis of First Row Transition Metals, Oxides and Hydroxides: $\mathrm{Cr}, \mathrm{Mn}, \mathrm{Fe}, \mathrm{Co}$ and Ni. Appl. Surf. Sci. 2011, 257, 2717-2730.

(26) Yamashita, T.; Hayes, P. Analysis of XPS Spectra of $\mathrm{Fe}^{2+}$ and $\mathrm{Fe}^{3+}$ Ions in Oxide Materials. Appl. Surf. Sci. 2008, 254, 2441-2449.

(27) Grosseau-Poussard, J. L.; Panicaud, B.; Pedraza, F.; Renault, P. O.; Silvain, J. F. Iron Oxidation under the Influence of Phosphate Thin Films. J. Appl. Phys. 2003, 94, 784.

(28) Pratt, A. R. Vivianite Auto-Oxidation. Phys. Chem. Miner. 1997, $25,24-27$.

(29) Khachani, M.; Kacimi, M.; Ensuque, A.; Piquemal, J.-Y.; Connan, C.; Bozon-Verduraz, F.; Ziyad, M. Iron-Calcium-Hydroxyapatite Catalysts: Iron Speciation and Comparative Performances in Butan-2-ol Conversion and Propane Oxidative Dehydrogenation. Appl. Catal., A 2010, 388, 113-123.

(30) Sun, S.; Zeng, H. Size-Controlled Synthesis of Magnetite Nanoparticles. J. Am. Chem. Soc. 2002, 124, 8204-8205.

(31) Fernane, F.; Mecherri, M. O.; Sharrock, P.; Hadioui, M.; Lounici, H.; Fedoroff, M. Sorption of Cadmium and Copper Ions on Natural and Synthetic Hydroxylapatite Particles. Mater. Charact. 2008, $59,554-559$.

(32) Sze, K. F.; Lu, Y. J.; Wong, P. K. Removal and Recovery of Copper Ion $\left(\mathrm{Cu}^{2+}\right)$ from Electroplating Effluent by a Bioreactor Containing Magnetite-Immobilized Cells of Pseudomonas putida 5X. Resour., Conserv. Recycl. 1996, 18, 175-193.

(33) Wong, K. S.; Wong, K. H.; Chung, W. K.; Wong, P. K. Adsorption of Copper Ion on Magnetite-Immobilised Chitin. Water Sci. Technol. 2007, 56, 135-143.

(34) Yamashita, Y.; Jaffe, R. Characterizing the Interactions Between Trace Metal and Dissolved Organic Matter Using Excitation-Emission Matrix and Parallel Factor Analysis. Environ. Sci. Technol. 2008, 42, 7374-7379.

(35) Senna, M. Determination of Effective Surface Area for the Chemical Reaction of Fine Particulate Materials. Part. Part. Syst. Charact. 1989, 6, 163-167.

(36) Murray, A. R.; Kisin, E. R.; Tkach, A. V.; Yanamala, N.; Mercer, R.; Young, S. H.; Fadeel, B.; Kagan, V. E.; Shvedov, A. A. Factoring-in 
Agglomeration of Carbon Nanotubes and Nanofibers for Better

Prediction of their Toxicity versus Asbestos. Part. Fibre Toxicol. 2012,

9, 10.

(37) De With, G.; Van Dijk, H. J. A.; Hattu, N.; Prijs, K. Preparation, Microstructure and Mechanical Properties of Dense Polycrystalline Hydroxyapatite. J. Mater. Sci. 1981, 16, 1592. 